\title{
Consistent Provisions Mitigate Exposure to Sexual Risk and HIV Among Young Adolescents in South Africa
}

\author{
Elona Toska ${ }^{1,2,3,10} \cdot$ Laurence Campeau $^{3} \cdot$ Lucie Cluver $^{3,4} \cdot$ F. Mark Orkin ${ }^{5} \cdot$ McKenzie N. Berezin $^{3,6} \cdot$ Lorraine Sherr $^{7}$. \\ Christina A. Laurenzi ${ }^{8}$. Gretchen Bachman ${ }^{9}$
}

Published online: 20 November 2019

(c) The Author(s) 2019

\begin{abstract}
Exposure to sexual risk in early adolescence strongly predicts HIV infection, yet evidence for prevention in young adolescents is limited. We pooled data from two longitudinal South African surveys, with adolescents unexposed to sexual risk at baseline $(n=3662)$. Multivariable logistic regression tested associations between intermittent/consistent access to eight provisions and reduced sexual risk exposure. Participants were on average 12.8 years, $56 \%$ female at baseline. Between baseline and follow-up, 8.6\% reported sexual risk exposure. Consistent access to caregiver supervision (OR $0.5395 \% \mathrm{CI}$ $0.35-0.80 \mathrm{p}=0.002)$, abuse-free homes (OR $0.5595 \% \mathrm{CI} 0.37-0.81 \mathrm{p}=0.002)$, school feeding (OR $0.5595 \% \mathrm{CI} 0.35-0.88$ $\mathrm{p}=0.012$ ), and HIV prevention knowledge (OR 0.43 , 95\% CI $0.21-0.88 \mathrm{p}=0.021)$ was strongly associated with preventing early sexual risk exposure. While individual factors reduced the odds of sexual risk exposure, a combination of all four resulted in a greater reduction, from $12.9 \%(95 \% \mathrm{CI} 7.2-18.7)$ to $1.0 \%$ (95\% CI $0.2-1.8$ ). Consistent access to provisions in early adolescence may prevent sexual risk exposure among younger adolescents.
\end{abstract}

Keywords Adolescents · South Africa · Sexual risk · HIV · Prevention

Meetings: Preliminary findings presented in this manuscript were presented at a satellite symposium hosted by the South African National AIDS Council at the International AIDS Conference in Amsterdam, the Netherlands in July 2018. Analyses accepted as oral presentation at the International AIDS Conference (Mexico City, July 2019) and AIDS Impact (London, July 2019).

Electronic supplementary material The online version of this article (https://doi.org/10.1007/s10461-019-02735-x) contains supplementary material, which is available to authorized users.

Elona Toska

Elona.Toska@uct.ac.za; Elona.Toska@gmail.com

1 AIDS and Society Research Unit, University of Cape Town, Cape Town, South Africa

2 Department of Sociology, University of Cape Town, Cape Town, South Africa

3 Department of Social Policy and Intervention, University of Oxford, Oxford, UK

4 Department of Child and Adolescent Psychiatry, Cape Town, South Africa

5 SAMRC Developmental Pathways for Health Research Unit, School of Clinical Medicine, University of Witwatersrand, Johannesburg, South Africa
6 Department of Applied Psychology, New York University, New York, NY, USA

7 Institute of Global Health, University College London, London, UK

8 Institute for Life Course Health Research, Faculty of Medicine and Health Sciences, Stellenbosch University, Tygerberg, South Africa

9 Office of HIV/AIDS, United States Agency for International Development, Arlington, VA, USA

10 University of Cape Town, 4.89 Leslie Social Science Building, 12 University Avenue South, Rondebosch, 7700 Cape Town, South Africa 


\section{Resumen}

La exposición al riesgo sexual en la adolescencia temprana predice fuertemente la infección por VIH, pero la evidencia para la prevención en adolescentes jóvenes es limitada. Reunimos datos de dos encuestas longitudinales sudafricanas, con adolescentes no expuestos al riesgo sexual al inicio del estudio $(n=3662)$. La regresión logística multivariable probó las asociaciones entre el acceso intermitente/constante a ocho disposiciones potenciales y la exposición al riesgo sexual reducida. Los participantes fueron en promedio 12.8 años, 56\% mujeres. Entre el inicio y el seguimiento, el 8.6\% informó exposición al riesgo sexual. Acceso constante a supervisión de un cuidador (OR 0.53 95\%CI 0.35-0.80 p =0.002), las casas sin abuso (OR $0.5595 \%$ CI $0.37-0.81 \mathrm{p}=0.002$ ), alimentación escolar (OR 0.55 95\%CI 0.35-0.88 p=0.012), y conocimiento de prevención del VIH (OR 0.43, 95\%CI 0.21-0.88 p =0.021) estuvo fuertemente asociado con la prevención de la exposición temprana al riesgo sexual. Si bien los factores individuales redujeron las probabilidades de exposición al riesgo sexual, una combinación de los cuatro resultó en una mayor reducción, de 12.9\% (IC 95\% 7.2-18.7) a 1.0\% (IC 95\% 0.2-1.8). El acceso constante a las disposiciones en la adolescencia temprana puede prevenir la exposición al riesgo sexual entre los adolescentes más jóvenes.

Palabras clave Adolescentes · Sudáfrica · Riesgo sexual · VIH · Prevención

\section{Introduction}

Despite overall reductions in total HIV incidence in Eastern and Southern Africa, rates of new infections among 15- to 24-year-old adolescent girls and young women remain unacceptably high, with an estimated 7000 new infections each week $[1,2]$. The risk of HIV infection increases progressively with age, with a significant increase among 16- to 17-year-old adolescent girls and 20- to 24-year-old young men [3]. This persistent incidence coincides with a rapidly growing adolescent population in the region, from 229 million in 2015 to an estimated 435 million in 2030 [4, 5]. Preventing new HIV infections among adolescents in Eastern and Southern Africa is critical in order to reduce adolescent mortality and morbidity [6].

Evidence examining exposure to sexual risk has largely focused on 15- to 24-year-old adolescent girls and young women, particularly given the strong association between sexual risk exposure and heterosexual HIV infection in this population in sub-Saharan Africa [7-9]. Early sexual debut, sex in exchange for goods or money, and age-disparate relationships among young women and older sexual partners also contribute to high HIV infection risk [10-16], including unintended pregnancies [17].

Evidence suggests that multi-level factors affect early exposure to sexual risk. Specifically, individual-level factors (poor knowledge of HIV transmission and prevention, low self-efficacy, and violence victimization), family-based factors (orphanhood, parent/caregiver-adolescent engagement and parental monitoring), household-based factors (poverty and food insecurity) [18], and school dropout [19-22] are closely associated with early exposure to sexual risk, including HIV infection. Supporting adolescents to remain in school protects them from HIV infection, unintended adolescent pregnancy, and sexually transmitted infections [23], especially for adolescent girls [24, 25]. To prevent new HIV infections among adolescents and young people, interventions need to address risk factors across the socioecological continuum [26-29]. However, among adolescents who remain enrolled in school, data is still needed to indicate which specific school-based provisions are most effective at preventing HIV infections and reducing early exposure to sexual risk. In particular, evidence on which types of subsidies should be applied to which subgroups of adolescents would support more effective delivery of HIV and sexual risk prevention services.

While we know about risk and protective factors for HIV infection among older adolescent girls and young women, there is less evidence on sexual risk among adolescents living with HIV [29]. Research on reducing sexual risk exposure among young adolescents, for those who are HIV uninfected as well as those living with HIV, is critical to breaking the cycle of HIV transmission. Reducing exposure to sexual risk has been associated with reduced new infections among young people and adults [30, 31]. For instance, increasing condom use amongst adolescents is a key strategy found to effectively reduce exposure to HIV among adolescents and young people [32]. Despite this data, evidence is needed to know what works in early adolescence, when many of these sexual risks first emerge, including which combinations of provisions have the highest impact to prevent exposure to sexual risk [33].

The evidence on HIV prevention efforts for adolescents and young people highlights the need to combine biomedical, individual and structural interventions to address the causal pathways to HIV infection during this vulnerable age [33-35]. Programming for younger adolescents is critical to developing resilience, initiating safe behaviors, and enabling early detection of risk factors [36]. However, improved access to quality and consistent services and programming for adolescents and young people is needed to achieve the highest reduction in HIV incidence [37]. Findings from a large dataset of South African adolescents showed that consistent access to the government-issued 
Child Support Grant was associated with reduced HIV risk behaviors [38]. Additional evidence on the effect of the timing and consistency of accessing HIV prevention programming for adolescents is needed, beyond government cash transfers. Longitudinal analyses are needed to show if, and how, access to single or combinations of services or provisions shapes early exposure to sexual risk, particularly among an age group rarely included in such research: 10- to 14-year-old adolescents.

We use data from two longitudinal data sets from two South African surveys to answer three research questions: (1) which provisions (alone and in combination) are associated with preventing exposure to sexual risk in early adolescence, (2) do associations of provisions with reduced sexual risk exposure vary by gender and residential location (urban/rural), and (3) how do differing levels of access to provisions over time influence early exposure to sexual risk?

\section{Methods}

This analysis draws upon the pooling of individual-level data from two existing independent longitudinal cohort studies, Young Carers and Mzantsi Wakho, based in three provinces of South Africa. The Young Carers study is a prospective cohort of $n=3401$ adolescents aged 10-17 living in two South African provinces, Mpumalanga and Western Cape. The cohort collected data between 2010 and 2012. Participants were recruited through door-to-door recruitment of two randomly-selected census enumeration areas in a rural and urban district in each province [39]. The Mzantsi Wakho study is a prospective cohort of $n=141010$ - to 19 -year-old adolescents of sero-assorted HIV status living in a health sub-district in the Eastern Cape province in South Africa, with data collected from 2014 to 2017. The longitudinal Mzantsi Wakho sample includes 1080 adolescents living with HIV, an important population for secondary HIV prevention efforts. The studies shared investigators and used similar data collection procedures, which are explained in more detail in prior publications $[39,40]$. The studies had high acceptability with low refusal rates $(<4 \%$ at both baseline and follow-up). During follow-up, $96.7 \%$ of Young Carers and $93.8 \%$ of Mzantsi Wakho participants were reinterviewed. Follow-up times averaged 353 days for Young Carers (range 77-829 days) and 571 days for Mzantsi Wakho (range 210-1091 days). Ethical approvals for data collection were obtained from Universities of Oxford (SSD/2/3/ IDREC and SSD/CUREC2/12-21), Cape Town (HREC 389/2009 and CSSR 2013/04), and the relevant provincial South African Departments of Health, Basic Education, and Social Development [39, 41].

\section{Data Pooling}

To minimize measurement bias, we pooled data following a rigorous examination of study data collection tools for conceptual and measurement validity [42]. All items were measured using identical tools across the two surveys, except for HIV knowledge, as detailed below. Questions measured the same phenomena within comparable time frames, and answer options were comparable for categorical variables. In cases where variables had a different number of categories between studies, the variable with the larger number of categories was reduced to be equivalent to the variable with the least categories [43]. We conducted a quality control check following variable harmonization, using cross-tabulations for categorical variables and five-number summary for continuous variables by sample. We investigated dissimilar category counts to ensure that differences in frequencies reflected actual differences between population, and not difference in definitions or data collection procedures. After completing this process, we computed estimates on the resulting dataset as one larger sample, controlling for original study location in each analysis.

\section{Ethics and Data Collection Procedures}

All participants 18 and over provided voluntary informed consent, and both caregiver and adolescent provided assent/ consent if participants were under 18 years old. Researchers fluent in local languages (Xhosa, Swati, Tsonga, and Sotho), who were trained to discuss sensitive topics with children and adolescents, conducted face-to-face interviews. Questionnaires were co-designed in consultation with a teen advisory group and piloted with adolescents from the study areas. Participants were interviewed in a location of their choosing, which maximized safety, confidentiality, and comfort throughout the interview. No financial remuneration was awarded for participating, but all adolescents received a snack pack and a study participation certificate. Participants at risk of harm or experiencing harm at the time of interview received support to link with emergency or support services, based on the recommendations of a trained social worker.

\section{Measures}

Full questionnaires are available at www.mzantsiwakho.co. za and www.youngcarers.org.za. The primary study outcome was exposure to sexual risk, measured as the incidence of at least one of four high-risk sexual experiences between baseline and follow-up: inconsistent condom use, transactional sex, age-disparate relationship, or early sexual debut. Inconsistent condom use referred to 'never, 'rarely' or 'sometimes' using condom during sexual intercourse in the past year. Transactional sex was past-year incidence of 
sex in exchange for food, shelter, school fees, transport, or money. Age-disparate relationship was past-year incidence of having a sexual partner more than 5 years older. Early sexual debut referred to having had a first sexual intercourse before the age of 18 years old. Past-year pregnancy/having made someone pregnant was recorded through self-reports for both adolescent girls and boys.

\section{Provisions}

A total of eight provisions were hypothesized to delay sexual risk exposure based on the existing evidence base: (1) strong parental/caregiver supervision; (2) positive parenting/ caregiving; (3) abuse-free homes; (4) school feeding; (5) affordable school materials; (6) affordable school fees; (7) government cash transfers; and (8) HIV prevention knowledge. Adolescents were recorded as experiencing or having access to these provisions or not at baseline and follow-up, and access was categorized as (1) no access at either baseline or follow-up; (2) intermittent access, defined as access at baseline or follow-up; (3) consistent access, measured as access at both baseline and follow-up.

Parenting/caregiver support was measured using two sub-scales of the Alabama Parenting Questionnaire [44, 45]. Strong parental/caregiver supervision was computed as adolescents choosing 'very good' on all six items about home rule-setting or monitoring of adolescent socializing, while positive parenting was measured as scoring 'very good' on all five items about caregiver-provided praise and positive reinforcement. Living in an abuse-free home was measured through adolescent self-reported monthly or more frequent experiences of physical or emotional violence at home [46]. Adolescent access to three types of educational subsidies was measured through adolescent self-reported access to: school feeding, defined as accessing at least one meal a day at school; affordable uniforms and school materials, measured as the adolescent's family being able to afford uniforms and school stationery; and affordable school fees, defined as access to fee-free schooling. Each subsidy was included as a separate provision in analyses. Government cash transfers was defined as access to at least one child-related government grant into the home, such as South Africa's Child Support Grant or Foster Child Grant. HIV prevention knowledge was measured as adolescent's correct knowledge of four items on different modes of HIV transmission and prevention methods, for example 'HIV cannot be passed from a HIV-positive mother to her unborn child.'

Additionally, analyses controlled for eight covariates across analyses, pre-selected for their potential effects on sexual risk exposure or access to social protection: (1) age; (2) gender; (3) urban/rural location; (4) formal/informal housing type; (5) province of residence; (6) socio-economic status (households were defined as poor if the adolescent reported missing at least one of eight basic necessities, such as "money to go to the doctor", or "three meals a day"); (7) orphanhood, defined as being both maternally and paternally orphaned, and (8) HIV status, determined through selfreported HIV-positive test or being on antiretroviral therapy.

\section{Analyses}

The final pooled dataset consisted of $n=4811$ participants. All participants who had been exposed to sexual risk prior to baseline data collection were excluded from analysis $(n=1149)$, to allow the analyses to identify provisions associated with exposure to sexual risk. Of the $n=3662$ (76\%) participants who reported no exposure to sexual risk at baseline, $97 \%$ were enrolled in school at both baseline and follow-up. We focused our analyses among adolescents enrolled in publicly-funded government schools in both data points, given high rates of enrolment at both times in this young sample, which reflect enrolment rates in other studies in South Africa [47]. To explore which provisions were associated with the outcome, we conducted final analyses using Stata 15 among $n=3635$ adolescents who did not report sexual risk at baseline and were enrolled at school at both times, with exposure to sexual risk at follow-up as the outcome. Missing data was minimal $(<1 \%)$ for all included variables.

First, we calculated descriptive statistics for all covariates, provisions included. We used comparison tests to compare adolescents exposed to sexual risk at follow-up and those who were not exposed, using two-sample t-tests for continuous variables and Pearson's $\chi^{2}$ tests for categorical variables (Table 1). We reported frequency distributions for longitudinal access to provisions (Table 2).

Second, to assess the validity of the self-reported study outcome, we tested whether exposure to sexual risk was associated with incident self-reported pregnancy or having made someone pregnant, using Pearson's $\chi^{2}$ test.

Third, we assessed associations between each level of access to provisions and exposure to sexual risk in multivariable logistic regressions using the three-step Hosmer-Lemeshow approach [48] (Table 3). In Model 1, we included all factors in a multivariable logistic regression with exposure to sexual risk as the outcome, controlling for all covariates. In Model 2, only variables associated with reduced sexual risk exposure at $\mathrm{p}<0.1$ in the previous model were included. In Model 3, we only included variables associated with the outcome at $\mathrm{p}<0.05$ level in the previous model.

Fourth, we tested potential interactions between all significant provisions to test for multiplicative effect. We then tested whether gender or rural residence moderated the association between the provisions and early sexual risk exposure, in light of evidence suggesting that HIV prevention programming may have different results by gender [49] and 
Table 1 Socio-demographic characteristics

\begin{tabular}{|c|c|c|c|c|}
\hline Variables at baseline $^{\mathrm{a}}$ & Total sample (n, \%) & No sexual risk $(\mathrm{n}, \%)$ & $\begin{array}{l}\text { Early sexual risk expo- } \\
\text { sure }(n, \%)\end{array}$ & $\begin{array}{l}\text { Com- } \\
\text { parison test } \\
(p-v a l u e)^{b}\end{array}$ \\
\hline Age (mean, range) & $12.8(9-19)$ & $12.7(9-19)$ & $14.4(10-19)$ & $<0.0001$ \\
\hline 9 & $10,0.3$ & $10,0.3$ & 0,0 & \\
\hline 10 & $555,15.3$ & $545,16.4$ & $10,3.2$ & \\
\hline 11 & $514,14.1$ & 49815.0 & $16,5.1$ & \\
\hline 12 & $628,17.3$ & $604,18.2$ & $24,7.6$ & \\
\hline 13 & $602,16.6$ & $562,16.9$ & $40,12.7$ & \\
\hline 14 & $537,14.8$ & $469,14.1$ & $68,21.7$ & \\
\hline 15 & $387,10.7$ & $311,9.4$ & $76,24.2$ & \\
\hline 16 & $229,6.3$ & $185,5.6$ & $44,14.0$ & \\
\hline 17 & $133,3.7$ & $108,3.3$ & $25,8.0$ & \\
\hline 18 & 28. 0.8 & $21,0.6$ & $7,2.2$ & \\
\hline 19 & $12,0.3$ & $8,0.2$ & $4,1.3$ & \\
\hline Age at follow-up (mean, range) & $14.1(10-21)$ & $14.0(10-21)$ & $16.0(11-21)$ & $<0.0001$ \\
\hline Gender & - & - & - & 0.897 \\
\hline Female & $2048,56.3$ & $1870,56.3$ & $178,56.7$ & - \\
\hline Male & $1587,43.7$ & $1451,43.7$ & $136,43.3$ & - \\
\hline Location type & - & - & - & $<0.0001$ \\
\hline Urban & $2110,58.0$ & $1886,56.8$ & $224,71.3$ & - \\
\hline Rural & $1524,42.0$ & $1434,43.2$ & $90,28.7$ & - \\
\hline Housing type & - & - & - & 0.349 \\
\hline Formal & $2733,75.2$ & $2490,75.0$ & $243,77.4$ & - \\
\hline Informal & $901,24.8$ & $830,25.0$ & $71,22.6$ & - \\
\hline Province of residence & - & - & - & $<0.0001$ \\
\hline Western Cape & $1154,31.8$ & $1087,32.7$ & $67,21.3$ & - \\
\hline Mpumalanga & $1412,38.8$ & $1363,41.0$ & $49,15.6$ & - \\
\hline Eastern cape & $1069,29.4$ & $871,26.2$ & $198,63.1$ & - \\
\hline Socio-economic status & - & - & - & 0.12 \\
\hline Any missing necessities at home & $2659,73.3$ & $2442,73.6$ & $217,69.6$ & - \\
\hline No missing necessities at home & $969,26.7$ & $874,26.4$ & $95,30.5$ & - \\
\hline Double orphanhood & - & - & - & 0.004 \\
\hline No & $3393,93.3$ & $3112,93.7$ & $281,89.5$ & - \\
\hline Yes & $242,6.7$ & $209,6.3$ & $33,10.5$ & - \\
\hline HIV status (follow-up) & - & - & - & $<0.0001$ \\
\hline HIV-positive & $835,23.2$ & $694,21.1$ & $141,45.2$ & - \\
\hline HIV-negative & $2771,76.8$ & $2600,78.9$ & $171,54.8$ & - \\
\hline
\end{tabular}

${ }^{a}$ All variables reported in this table were measured at baseline unless noted otherwise

bTwo-sample t-tests were used for continuous variables and Pearson's $\chi^{2}$ tests were used for categorical variables

location of delivery. We tested moderation using two-way interaction terms of each factor and either gender or rural residence in multivariable regressions, including all other covariates.

Lastly, we entered all provisions significantly associated with the outcome in the final model into a marginal effect model using multivariable logistic regression with covariates held at their mean values (Table 3). We calculated predicted probabilities of the outcome according to level of access to provisions (no access, intermittent access, consistent access) as well as according to the type of access (no intervention, single intervention or combination of all interventions) (Fig. 1). 
Table 2 Access to supportive and protective provisions

\begin{tabular}{llll}
\hline Provisions & No access (n, \%) & $\begin{array}{l}\text { Intermittent access } \\
(\mathrm{n}, \%)\end{array}$ & $\begin{array}{l}\text { Consistent } \\
\text { access }(\mathrm{n}, \\
\%)\end{array}$ \\
\hline Strong parental/caregiver supervision & $1088,30.0$ & $1598,44.1$ & $940,25.9$ \\
Positive parenting & $1601,44.0$ & $1388,38.2$ & $646,17.8$ \\
Abuse-free home & $856,23.6$ & $1553,42.8$ & $1224,33.7$ \\
School feeding scheme & $282,7.8$ & $310,8.6$ & $3033,83.7$ \\
Affordable school materials & $2043,56.2$ & $1021,28.1$ & $571,15.7$ \\
Affordable school fees & $189,5.2$ & $797,21.9$ & $2649,72.9$ \\
Government cash transfers & $284,7.9$ & $626,17.3$ & $2706,74.8$ \\
HIV prevention knowledge & $2818,86.0$ & $390,11.9$ & $69,2.1$ \\
\hline
\end{tabular}

\section{Results}

\section{Participant Characteristics and Outcome}

Participants were, on average, 12.8 years old (SD 2.0, range 9-19 years) at baseline and 14.1 years old at followup (SD 2.1, range 10-21 years), and 56\% were female. They lived in three provinces (Eastern Cape $29.4 \%$, Western Cape 31.8\% and Mpumalanga 38.8\%), with over half living in urban areas (58\%), the majority of whom were participants from urban communities in the Eastern Cape. Three-quarters lived in formal housing; another threequarters lived in households lacking at least one basic necessity, such as food or sufficient money for school fees. Overall, $6.7 \%$ of the sample were orphaned.

Notably, $8.6 \%$ of participants reported sexual risk exposure between baseline and follow-up. This self-reported outcome was strongly associated with reporting pregnancy or having made someone pregnant during the study period incident pregnancy (Pearson's $\chi^{2}(1)=109.5, p \leq 0.001$ ). In bivariate analyses, adolescents who reported exposure to sexual risk were older, more likely to be orphaned, living in urban areas, and living in the Eastern Cape (Table 1).

\section{Access to Provisions}

Three levels of access to a total of eight provisions are reported in Table 2. Only one-quarter of adolescents reported consistent access to strong parental supervision, and less than one in five received consistent positive parenting. A third of adolescents reported living in abuse-free homes at both baseline and follow-up, while nearly threequarters accessed government cash transfers consistently at baseline and follow-up. Only $2.1 \%$ of the sample had correct HIV knowledge, which may be explained due to the young age of the participants.

\section{Provisions Associated with Exposure to Sexual Risk}

Four provisions were associated with reduced odds of exposure to sexual risk. Adolescents receiving consistent parenting/caregiver supervision were $47 \%$ less likely to report sexual risk exposure (OR $0.5395 \%$ CI $0.35-0.80 \mathrm{p}=0.002$ ). Living in abuse-free homes at both baseline and follow-up was associated with a $45 \%$ reduction in the odds of sexual risk exposure (OR 0.55 95\% CI 0.37-0.81 $\mathrm{p}=0.002$ ). Receiving at least one meal a day at school consistently reduced the odds of sexual risk exposure by $45 \%$ (OR 0.55 $95 \%$ CI $0.35-0.88 \mathrm{p}=0.012$ ). HIV prevention knowledge was also associated with reduced sexual risk exposure, with a stronger impact on consistent correct HIV prevention knowledge: adolescents who had the correct knowledge at baseline and follow-up were $57 \%$ less likely to report sexual risk exposure compared to no access (OR $0.4395 \%$ CI $0.21-0.88$ $\mathrm{p}=0.021$ ), while those who had inconsistent HIV prevention knowledge were likely to report a $32 \%$ reduction in sexual risk exposure (OR 0.68 95\% CI 0.47-0.99 $\mathrm{p}=0.044$ ).

Combinations of consistent provisions, compared with single consistent provisions, were associated with lower odds of sexual risk exposure (Supplementary Table 1). Consistent access to each factor reduced the probability of reporting sexual risk exposure from $12.9 \%$ (95\% CI 7.2-18.7) without any access to provisions, to $1.0 \%$ (95\% CI $0.2-1.8$ ) with consistent access to all four provisions (Fig. 1). Most of the participants accessed at least one provision (51.9\%), followed by $30.8 \%$ of adolescents that accessed two provisions, $8.5 \%$ who accessed three of the four provisions and a handful $(\mathrm{n}=7,0.2 \%)$ who accessed all four of the provisions. About $10 \%$ of the adolescents did not access any of the provisions.

Older age and living in the Eastern Cape province remained significantly associated with exposure to sexual risk in the final model. There were no two- or three-way interactions among the four provisions significantly associated to reduced exposure to sexual risk (data not shown). Gender moderated the effect of the association between 
Table 3 Multivariable regression model of provisions associated with incident sexual risk exposure

\begin{tabular}{|c|c|c|c|c|c|c|c|c|c|}
\hline \multirow[t]{2}{*}{ Outcome measure: incident high-risk sex } & \multicolumn{3}{|l|}{ Model 1} & \multicolumn{3}{|c|}{ Model 2} & \multicolumn{3}{|c|}{ Model 3} \\
\hline & Odds ratio $(\mathrm{OR})$ & p-value & $95 \% \mathrm{CI}$ & OR & p-value & $95 \% \mathrm{CI}$ & OR & $\mathrm{p}$-value & $95 \% \mathrm{CI}$ \\
\hline Age & 1.43 & $<0.0001$ & $1.33-1.54$ & 1.42 & $<0.0001$ & $1.32-1.52$ & 1.42 & $<0.0001$ & $1.32-1.52$ \\
\hline Gender-female & 1.01 & 0.994 & $0.77-1.33$ & - & - & - & - & - & - \\
\hline Rural residence & 0.82 & 0.222 & $0.60-1.13$ & - & - & - & - & - & - \\
\hline Informal housing (reference category: formal) & 1.04 & 0.835 & $0.73-1.49$ & - & - & - & - & - & - \\
\hline \multicolumn{10}{|l|}{ Province (reference category: Eastern Cape) } \\
\hline Western Cape & 0.20 & $<0.0001$ & $0.11-0.35$ & 0.19 & $<0.0001$ & $0.13-0.27$ & 0.17 & $<0.0001$ & $0.12-0.25$ \\
\hline Mpumalanga & 0.09 & $<0.0001$ & $0.05-0.16$ & 0.08 & $<0.0001$ & $0.05-0.12$ & 0.07 & $<0.0001$ & $0.05-0.11$ \\
\hline $\begin{array}{l}\text { Socio-economic status (reference category: } \\
\text { household poverty) }\end{array}$ & 0.87 & 0.499 & $0.58-1.31$ & - & - & - & - & - & - \\
\hline Double orphanhood & 0.86 & 0.518 & $0.53-1.37$ & - & - & - & - & - & - \\
\hline HIV status (positive) & 1.04 & 0.876 & $0.67-1.60$ & - & - & - & - & - & - \\
\hline \multicolumn{10}{|l|}{ Supportive factors or provisions } \\
\hline \multicolumn{10}{|c|}{ Parental/caregiver support—-strong parental supervision ${ }^{\mathrm{a}}$} \\
\hline Intermittent access & 0.76 & 0.082 & $0.55-1.04$ & 0.75 & 0.072 & $0.55-1.03$ & 0.76 & 0.082 & $0.56-1.04$ \\
\hline Consistent access & 0.52 & 0.002 & $0.34-0.78$ & 0.53 & 0.002 & $0.35-0.80$ & 0.53 & 0.002 & $0.35-0.80$ \\
\hline \multicolumn{10}{|l|}{ Parental/caregiver support - Positive parenting } \\
\hline Intermittent access & 0.78 & 0.155 & $0.56-1.10$ & - & - & - & - & - & - \\
\hline Consistent access & 0.99 & 0.958 & $0.66-1.48$ & - & - & - & - & - & - \\
\hline \multicolumn{10}{|l|}{ Abuse-free homes } \\
\hline Intermittent access & 0.96 & 0.804 & $0.67-1.36$ & 0.92 & 0.636 & $0.65-1.30$ & 0.92 & 0.648 & $0.66-1.30$ \\
\hline Consistent access & 0.57 & 0.006 & $0.39-0.85$ & 0.54 & 0.002 & $0.37-0.79$ & 0.55 & 0.002 & $0.37-0.81$ \\
\hline \multicolumn{10}{|l|}{ School feeding scheme } \\
\hline Intermittent access & 0.88 & 0.687 & $0.48-1.62$ & 0.85 & 0.585 & $0.46-1.54$ & 0.86 & 0.615 & $0.47-1.55$ \\
\hline Consistent access & 0.61 & 0.054 & $0.36-1.01$ & 0.57 & 0.025 & $0.35-0.93$ & 0.55 & 0.012 & $0.35-0.88$ \\
\hline \multicolumn{10}{|c|}{ Educational subsidies—affordable school materials } \\
\hline Intermittent access & 1.52 & 0.03 & $1.04-2.22$ & 1.34 & 0.059 & $0.99-1.82$ & - & - & - \\
\hline Consistent access & 1.15 & 0.654 & $0.62-2.14$ & 1.02 & 0.942 & $0.63-1.64$ & - & - & - \\
\hline \multicolumn{10}{|c|}{ Educational subsidies - Fee-free school or affordable fees } \\
\hline Intermittent access & 0.78 & 0.402 & $0.43-1.40$ & - & - & - & - & - & - \\
\hline Consistent access & 0.78 & 0.375 & $0.44-1.36$ & - & - & - & - & - & - \\
\hline \multicolumn{10}{|l|}{ Government cash transfers } \\
\hline Intermittent access & 1.08 & 0.799 & $0.58-2.01$ & - & - & - & - & - & - \\
\hline Consistent access & 1.20 & 0.531 & $0.68-2.12$ & - & - & - & - & - & - \\
\hline \multicolumn{10}{|l|}{ HIV prevention knowledge } \\
\hline Intermittent access & 0.71 & 0.073 & $0.49-1.03$ & 0.69 & 0.045 & $0.47-0.99$ & 0.68 & 0.044 & $0.47-0.99$ \\
\hline Consistent access & 0.43 & 0.022 & $0.21-0.88$ & 0.43 & 0.023 & $0.21-0.89$ & 0.43 & 0.021 & $0.21-0.88$ \\
\hline
\end{tabular}

${ }^{a}$ All results for provisions accessed intermittently or consistently use no access as a reference category

school feeding and sexual risk exposure, with no other significant moderation effects (Supplementary Tables 2 and 3 ). The effect of accessing school feeding (whether intermittently or consistently) was stronger among young adolescent boys than adolescent girls, with consistent access to school feeding among boys resulting in the highest reduction in the probability of reporting exposure to sexual risk (Fig. 2).

\section{Discussion}

The findings from this secondary analysis of data from two large, longitudinal studies in South Africa demonstrate significant associations between four provisions and reduced exposure to sexual risk in early adolescence. These longitudinal data provide additional evidence that can shape current and future programming for HIV prevention for adolescents in South Africa and similar HIV risk contexts. It capitalizes 
Fig. 1 Probability of incident sexual risk exposure by combination of consistent access to provisions

Fig. 2 Probability of incident sexual risk exposure by gender and access to school feeding scheme

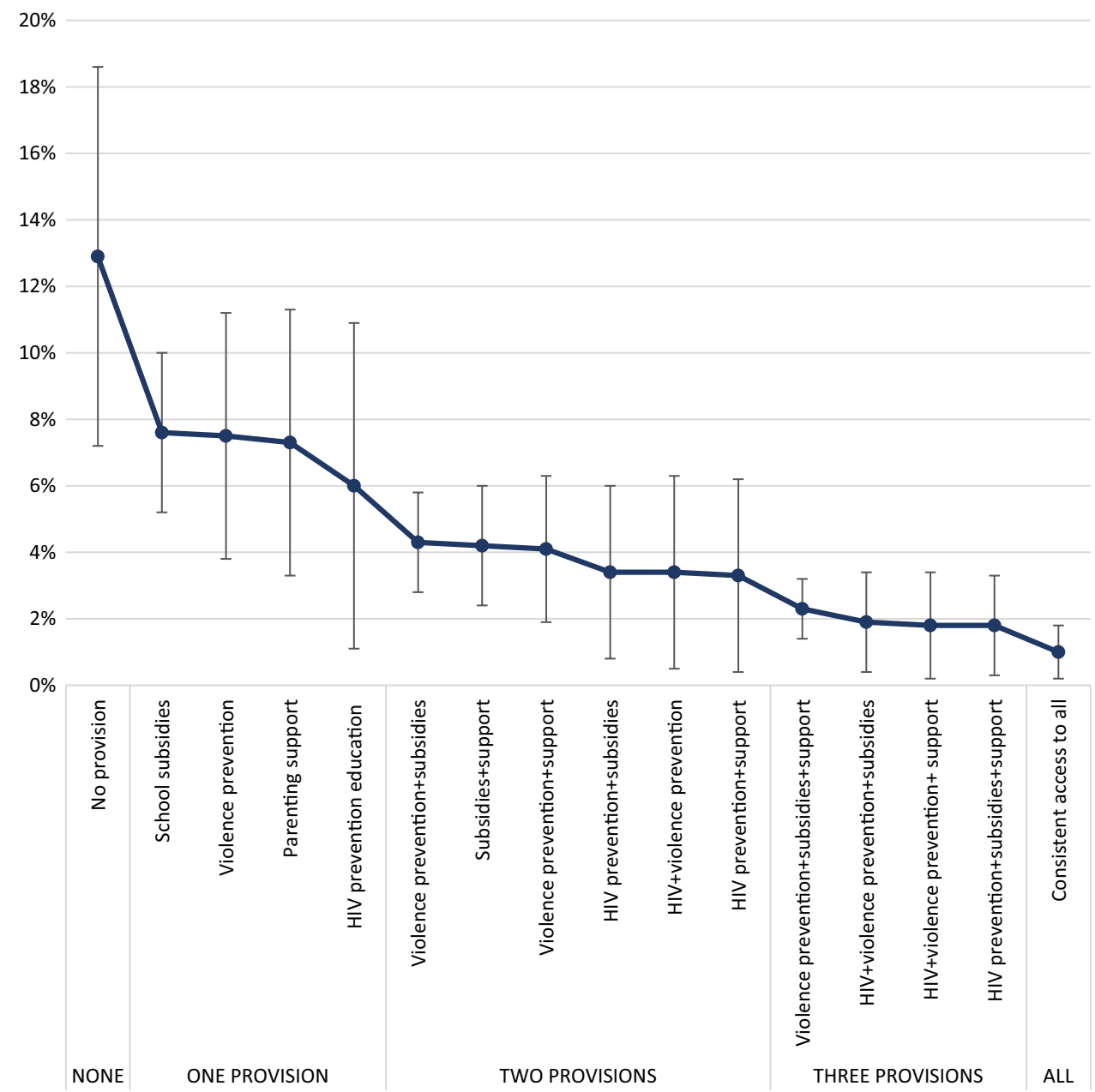

$18.0 \%$

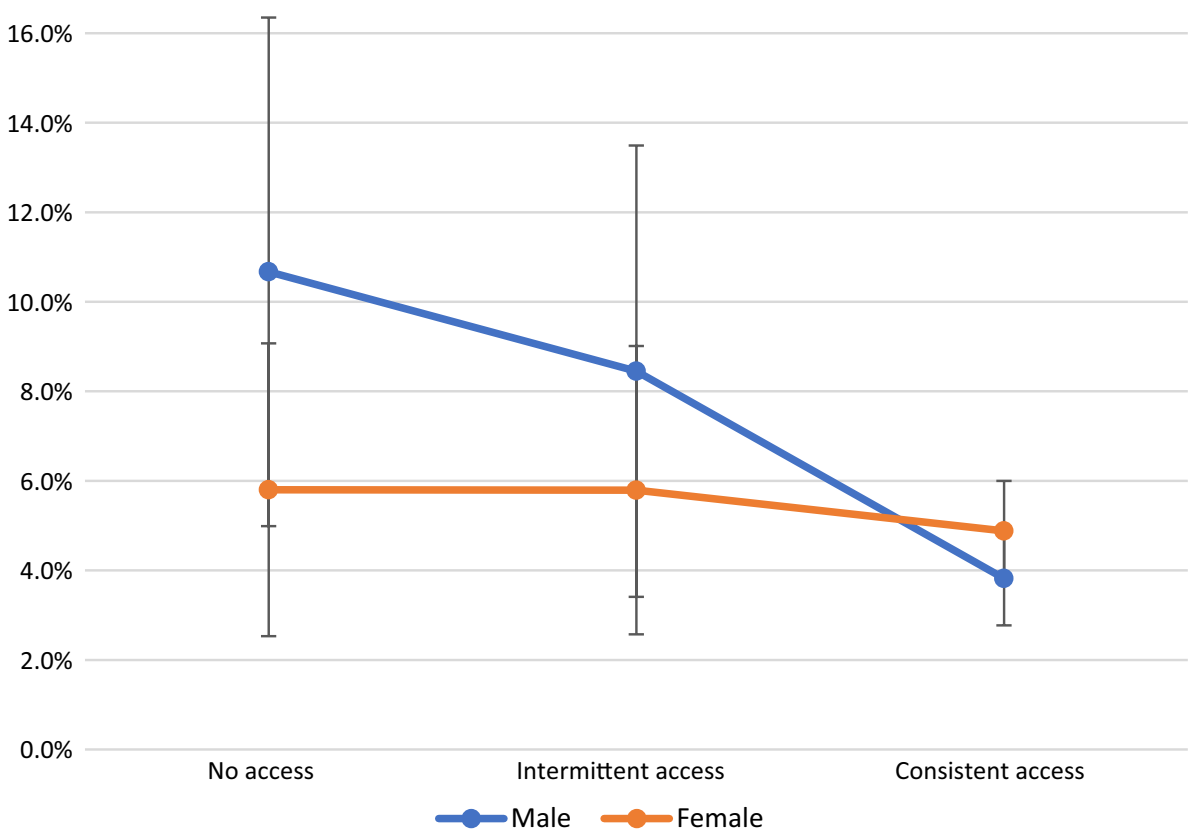


on two large-scale prospective surveys of early adolescents to draw lessons on factors that shape the onset of exposure to sexual risk and HIV, in the transition from early to middle adolescence, which are critical for programming for this early age group [50]. Most adolescent-focused research and programming targets older adolescents, particularly 15 - to 24-year-old girls and young women, but these new findings suggest an additional impact of providing such programs to younger girls and boys. These provisions-parental supervision, abuse-free homes, school feeding and HIV prevention knowledge — could be provided through home- and schoolbased programming.

Four provisions were associated with reduced odds of sexual risk exposure. Each provision individually reduced the odds of sexual risk exposure from $32 \%$ (OR $0.6895 \% \mathrm{CI}$ $0.47-0.99 \mathrm{p}=0.044)$ to $57 \%$ (OR $0.4395 \%$ CI $0.21-0.88$ $\mathrm{p}=0.021$, highlighting the importance of accessing provisions in early adolescence consistently to address longterm vulnerabilities and risks faced by South African adolescents and young people. Importantly, combinations of interventions resulted in a $92 \%$ reduction in the probability of reporting sexual risk exposure, from $12.9 \%$ (95\% CI $7.2-18.7$ ) to $1.0 \%$ (95\%CI $0.2-1.8$ ). Only two out of five participants accessed multiple provisions, although just over half accessed at least one of them. One in 12 adolescents in this sample reported sexual risk exposure over a one-year period - a high rate considering that $99 \%$ of participants were under 18 years old at baseline. Access to government cash transfers was not associated with sexual risk exposure, but this may be linked to lower access to cash transfers in the highest-risk group of older girls. Our findings confirm the importance of investing in early adolescence to reduce poorer health and educational outcomes in later adolescence [36]. This is particularly relevant considering findings from the Violence Against Children Survey suggest high rates of coercion and violence during first sexual encounters in Southern Africa [51].

An important finding of our analyses is that intermittent access to provisions-access at either baseline or follow-up, but not both-does not reduce the likelihood of sexual risk exposure, with the exception of HIV knowledge. However, consistent access over a full year in early adolescence to provisions may have substantial impacts in delaying sexual risk exposure. Gender did not moderate the association between the provisions and sexual risk exposure, with the exception of school feeding. This finding suggests that in early adolescence, the same combination of interventions may support both boys and girls, whether they live in rural or urban communities, to prevent sexual risk exposure and the possibility of HIV infection. The significantly stronger effect of school feeding schemes on reducing sexual risk exposure among adolescent boys needs to be further investigated. As programming increasingly focuses on 15 - to 24 -year-old adolescent girls, it is critical to provide consistent access to provisions that, in early adolescence, may have long-term benefits for both adolescent boys and girls.

This study has several limitations. Our sample of adolescents was still young, and consequently their reported exposure to sexual risk is lower than the risk they will experience throughout the course of adolescence and early adulthood. We can expect higher rates of sexual risk exposure among older adolescents. However, there is insufficient research with young adolescents, and this study provides critical information about this age group. Another limitation is linked to the number of provisions measured. The pooled data only included shared measures for eight possible factors. Third, this study did not collect biomarker data, such as HIV incidence using clinical test results. Nonetheless, in light of strong linkages documenting sexual risk exposure in early adolescence and HIV incidence [13, 52, 53], our findings contribute to an understanding of how to break pathways leading to HIV infection among adolescents and young people.

Despite these limitations, our longitudinal analyses with an under-researched age group provide valuable information for future programming seeking to reduce HIV incidence among adolescents and young people. While sustaining programming that reaches the highest-risk groups, namely 15- to 24-year-old young women, is essential, these findings show a substantive impact on younger adolescents-including boys - and those who have not yet initiated sexual activity or been exposed to sexual risk. They suggest that early, consistent access to protective programming at home and school-programming that focuses on reducing food insecurity, boosting caregiver-adolescent engagement, improving correct HIV prevention knowledge, and preventing violence in the home-is critical to preventing sexual risk exposure among vulnerable young people.

Acknowledgements We want to acknowledge the incredible contribution of all study participants, their families and the two research teams, without whom collecting this data would not be possible. The ASPIRES team at FHI360 provided invaluable support, especially Jennine Carmichael and Michael Ferguson. Thank you to Emily Namey and Holly Burke for their thoughts and feedback. The USAID/PEPFAR Orphans and Vulnerable Children team were involved in conceptualizing research questions.

Funding This research was supported by the Evidence for HIV Prevention in Southern Africa (EHPSA), a UK aid programme managed by Mott MacDonald, Janssen Pharmaceutica N.V., part of the Janssen Pharmaceutical Companies of Johnson \& Johnson, by the Medical Research Council (MRC) and the Department of Health Social Care (DHSC) through its National Institutes of Health Research (NIHR) [MR/R022372/1] funded under the MRC/DFID Concordat agreement, and the Nuffield Foundation [CPF/41513; OPD/31598], but the views expressed are those of the authors and not necessarily those of the Foundation, the Regional Inter-Agency Task Team for Children Affected by AIDS-Eastern and Southern Africa (RIATT-ESA), the International AIDS Society through the CIPHER grant (155-Hod; 
2018/625-TOS), Claude Leon Foundation [F08 559/C], the South African National Department of Social Development [27/2011/11 HIV AND AIDS], the Health Economics and HIV/AIDS Research Division (HEARD) at the University of KwaZulu-Natal [R14304/AA002] and the South African National Research Foundation [RES-062-23-2068]. Additional support for the team is provided by: University of Oxford's ESRC Impact Acceleration Account (IAA) [K1311-KEA-004 \& 1602KEA-189], the Economic and Social Research Council [IAA-MT13003], the Canadian International Development Agency, the John Fell Fund [103/757 \& 161/033], the Leverhulme Trust [PLP-2014-095], UNICEF Eastern and Southern Africa Office (UNICEF-ESARO), and the Oak Foundation [R46194/AA001]. Additional support was provided by the Economic and Social Research Council UK (LS), the European Research Council (ERC) under the European Union's Seventh Framework Programme [FP7/2007-2013]/ ERC Grant Agreement No. 313421, the European Union's Horizon 2020 research and innovation programme (Grant Agreement No. 737476) (LC, LCa). Further support was provided by Oxford University Clarendon-Green Templeton College Scholarship (ET). The views expressed in written materials or publications do not necessarily reflect the official policies of the International AIDS society. This publication was produced under United States Agency for International Development (USAID) Cooperative Agreement No. AID-OAA-LA-13-00001 and was made possible by the generous support of the American people through USAID and the United States President's Emergency Plan for AIDS Relief. The contents are the responsibility of FHI 360 and Oxford University and do not necessarily reflect the views of USAID or the United States Government (MO, LS)

Open Access This article is distributed under the terms of the Creative Commons Attribution 4.0 International License (http://creativeco mmons.org/licenses/by/4.0/), which permits unrestricted use, distribution, and reproduction in any medium, provided you give appropriate credit to the original author(s) and the source, provide a link to the Creative Commons license, and indicate if changes were made.

\section{References}

1. UNAIDS JUNP on H. 2017 Global Hiv Statistics - Fact Sheet [Internet]. Geneva, Switzerland; 2018. http://www.unaids.org/sites /default/files/media_asset/UNAIDS_FactSheet_en.pdf.

2. Human Sciences Research Council (HSRC). The Fifth South African National HIV Prevalence, Incidence, Behaviour and Communication Survey, 2017: HIV Impact Assessment Summary Report. Cape Town, South Africa; 2018.

3. Shisana O, Rehle TM, Simbayi LC, Zuma K, Jooste S, Zungu NP, et al. South African National HIV prevalence, incidence and behaviour survey, 2012. Cape Town: HSRC Press; 2014.

4. UNDESA. World Population Prospects: The 2017 Revision. 2017.

5. UNICEF. For Every Child, End AIDS - Seventh Stocktaking Report, 2016 [Internet]. New York, USA; 2016. www.childrenan daids.org.

6. UNAIDS JUNP on H. Miles To Go: Closing Gaps, Breaking Barriers, Righting Injustices [Internet]. Global AIDS Update. Geneva, Switzerland; 2018. https://doi.org/10.111 1/j.1600-6143.2011.03542.x.

7. Pettifor A, Rees H, Kleinschmidt I, Steffenson A, MacPhail C, Hlongwa-Madikizela L, et al. Young people's sexual health in South Africa: HIV prevalence and sexual behaviors from a nationally representative household survey. AIDS. 2005;19(14):1525-34.
8. Steffenson AE, Pettifor AE, Seage GR 3rd, Rees HV, Cleary PD. Concurrent sexual partnerships and human immunodeficiency virus risk among South African youth. Sex Transm Dis. 2011;38:459-66. https://doi.org/10.1097/OLQ.0b013e318208086 0.

9. Pascoe SJS, Langhaug LF, Mavhu W, Hargreaves JR, Jaffar S, Hayes RJ, et al. Poverty, food insufficiency and HIV infection and sexual behaviour among young rural Zimbabwean women. PLoS ONE. 2015;10:e0115290. https://doi.org/10.1371/journ al.pone. 0115290 .

10. Wand H, Ramjee G. The relationship between age of coital debut and HIV seroprevalence among women in Durban, South Africa: a cohort study. BMJ Open. 2012;2:e000285.

11. Ghebremichael M, Larsen U, Paintsil E. Association of age at first sex with HIV-1, HSV-2 and other sexual transmitted infections among women in northern Tanzania. Sex Transm Dis. 2009;36:570.

12. Rositch AF, Cherutich P, Brentlinger P, Kiarie JN, Nduati R, Farquhar C. HIV infection and sexual partnerships and behaviour among adolescent girls in Nairobi, Kenya. Int J STD AIDS. 2012;23:468-74. https://doi.org/10.1258/ijsa.2012.011361.

13. Stöckl H, Kalra N, Jacobi J, Watts C. Is early sexual debut a risk factor for HIV infection among women in Sub-Saharan Africa? A systematic review. Am J Reprod Immunol. 2013. https://doi. org/10.1111/aji.12043.

14. Wamoyi J, Fenwick A, Urassa M, Zaba B, Stones W. Parent-child communication about sexual and reproductive health in rural Tanzania : implications for young people's sexual health interventions. Reprod Health. 2010;7(1):6.

15. Kilburn K, Ranganathan M, Stoner MCD, Hughes JP, MacPhail C, Agyei Y, et al. Transactional sex and incident HIV infection in a cohort of young women from rural South Africa. AIDS. 2018;32:1669.

16. Luke N, Kurz K. Cross-generational and transactional sexual relations in sub-Saharan Africa. Washington, DC: DC Int Cent Res Women; 2002.

17. Toska E, Cluver LD, Boyes ME, Pantelic M, Kuo C. From, "sugar daddies" to "sugar babies": quantitatively testing the pathway between inequitable sexual relationships, condom use, and adolescent pregnancy in South Africa. Sex Health. 2015;12:59-66.

18. Lee RLT, Yuen Loke A, Hung TTM, Sobel H. A systematic review on identifying risk factors associated with early sexual debut and coerced sex among adolescents and young people in communities. J Clin Nurs. 2018;27:478-501. https://doi.org/10.1111/jocn.13933

19. Speizer IS, Guilkey D, Calhoun LM, Corroon M, O'Hara R. Examination of youth sexual and reproductive health transitions in Nigeria and Kenya using longitudinal data. BMC Public Health. 2017;17:1-16. https://doi.org/10.1186/s12889-017-4039-8.

20. Odimegwu C, Somefun OD, Chisumpa VH. Regional differences in positive sexual behaviour among youth in sub-Saharan Africa. J Biosoc Sci. 2018. https://doi.org/10.1017/s002193201800010x.

21. Fetene N, Mekonnen W. The prevalence of risky sexual behaviors among youth center reproductive health clinics users and nonusers in Addis Ababa, Ethiopia: a comparative cross-sectional study. PLoS ONE. 2018;13:1-16. https://doi.org/10.1371/journ al.pone. 0198657 .

22. Robert Dlamini B, Mabuza P, Masangane Z, Silindza T, Dlamini M, Dlamini P. The HIV and sexual reproductive health status of young people in Swaziland: the rationale for focused youth investment. J AIDS Clin Res. 2017. https://doi.org/10.4172/21556113.1000669.

23. Cho H, Hallfors DD, Mbai II, Itindi J, Milimo BW, Halpern CT, et al. Keeping adolescent orphans in school to prevent human immunodeficiency virus infection: evidence from a randomized 
controlled trial in Kenya. J Adolesc Health. 2011;48:523-6. https ://doi.org/10.1016/j.jadohealth.2010.08.007.

24. Odimegwu C, Somefun OD. Ethnicity, gender and risky sexual behaviour among Nigeria youth: an alternative explanation. Reprod Health. 2017;14:1-15. https://doi.org/10.1186/s1297 8-017-0284-7.

25. Glynn JR, Sunny BS, DeStavola B, Dube A, Chihana M, Price AJ, et al. Early school failure predicts teenage pregnancy and marriage: a large population-based cohort study in northern Malawi. PLoS ONE. 2018;13:1-17. https://doi.org/10.1371/journ al.pone.0196041.

26. Pretorius L, Gibbs A, Crankshaw T, Willan S. Interventions targeting sexual and reproductive health and rights outcomes of young people living with HIV: a comprehensive review of current interventions from sub-Saharan Africa. Glob Health Action. 2015;8:28454. https://doi.org/10.3402/gha.v8.28454.

27. Pettifor A, Lippman SA, Selin AM, Peacock D, Gottert A, Maman $\mathrm{S}$, et al. A cluster randomized-controlled trial of a community mobilization intervention to change gender norms and reduce HIV risk in rural South Africa: study design and intervention. BMC Public Health. 2015;15:1-7. https://doi.org/10.1186/s1288 9-015-2048-z.

28. Toska E, Gittings L, Hodes R, Cluver L, Govender K, Chademana $\mathrm{E}$, et al. Resourcing resilience: social protection for HIV prevention amongst children and adolescents in Eastern and Southern Africa. African J AIDS Res. 2016;15(2):123-40.

29. Toska E, Pantelic M, Meinck F, Keck K, Haghighat R, Cluver L. Sex in the shadow of HIV: a systematic review of prevalence rates, risk factors and interventions to reduce sexual risk-taking among HIV-positive adolescents and youth in Sub-Saharan Africa. PLoS ONE. 2017;12:e0178106.

30. Sandøy IF, Michelo C, Siziya S, Fylkesnes K. Associations between sexual behaviour change in young people and decline in HIV prevalence in Zambia. BMC Public Health. 2007;7:60.

31. Kincaid DL, Babalola S, Figueroa ME. HIV communication programs, condom use at sexual debut, and HIV infections averted in South Africa, 2005. JAIDS J Acquir Immune Defic Syndr. 2014;66:S278-84.

32. UNAIDS. GLOBAL REPORT: UNAIDS report on the global AIDS epidemic 2013. Unaids. 2013. JC2502/1/E

33. Pettifor A, Nguyen NL, Celum C, Cowan FM, Go V, HightowWeidman L. Tailored combination prevention packages and PrEP for young key populations. J Int AIDS Soc. 2015. https://doi. org/10.7448/ias.18.2.19434.

34. Cluver LD, Orkin FM, Yakubovich AR, Sherr L. Combination social protection for reducing HIV-risk behavior amongst adolescents in South Africa. J Acquir Immune Defic Syndr. 2016;72:96104. https://doi.org/10.1097/QAI.0000000000000938.

35. Delany-Moretlwe S, Cowan FM, Busza J, Bolton-Moore C, Kelley K, Fairlie L. Providing comprehensive health services for young key populations: needs, barriers and gaps. J Int AIDS Soc. 2015;18:19833. https://doi.org/10.7448/IAS.18.2.19833.

36. Lane C, Brundage CL, Kreinin T. Why we must invest in early adolescence: early intervention, lasting impact. J Adolesc Health. 2017;61:S10-1. https://doi.org/10.1016/j.jadohealth.2017.07.011.

37. Mavedzenge SMN, Doyle AM, Ross DA. HIV prevention in young people in sub-Saharan Africa: a systematic review. J Adolesc Health. 2011;49:568-86.

38. Cluver LD, Boyes ME, Orkin MF, Pantelic M, Molwena T, Sherr L. Child-focused state cash transfers and adolescent risk of HIV infection in South Africa: a propensity-score-matched casecontrol study. Lancet Glob Health. 2013;1:e362-70. https://doi. org/10.1016/S2214-109X(13)70115-3.

39. Cluver L, et al. Parenting for Lifelong Health: a pragmatic cluster randomised controlled trial of a non-commercialised parenting programme for adolescents and their families in South Africa. BMJ Glob Health. 2017;3:1-15. https://doi.org/10.1136/bmjgh -2017-000539.

40. Toska E, Cluver LD, Boyes ME, Isaacsohn M, Hodes R, Sherr L. School, supervision and adolescent-sensitive clinic care: combination social protection and reduced unprotected sex among HIVpositive adolescents in South Africa. AIDS Behav. 2016. https:// doi.org/10.1007/s10461-016-1539-y.

41. Cluver L, Pantelic M, Orkin M, Toska E, Medley S, Sherr L. Sustainable Survival for adolescents living with HIV: do SDGaligned provisions reduce potential mortality risk. J Int AIDS Soc. 2018;21:4-9. https://doi.org/10.1002/jia2.25056.

42. Richter LM, Orkin FM, Roman GD, Dahly DL, Horta BL, Bhargava SK, et al. Comparative models of biological and social pathways to predict child growth through age 2 years from birth cohorts in Brazil, India, the Philippines, and South Africa. J Nutr. 2018;148:1364-71. https://doi.org/10.1093/jn/nxy101.

43. Van der Steen JT, Kruse RL, Szafara KL, Mehr DR, van der Wal G, Ribbe MW, et al. Benefits and pitfalls of pooling datasets from comparable observational studies: combining US and Dutch nursing home studies. Palliat Med. 2008;22:750-9.

44. Frick PJ. The Alabama Parenting Questionnaire. 1991.

45. Lachman JM, Cluver LD, Boyes ME, Kuo C, Casale M. Positive parenting for positive parents: HIV/AIDS, poverty, caregiver depression, child behavior, and parenting in South Africa. AIDS Care. 2014;26:304-13. https://doi.org/10.1080/09540 121.2013.825368.

46. Meinck F, Cluver LD, Boyes ME, Loening-Voysey H. Physical, emotional, and sexual abuse of children in South Africa: incidence, prevalence, perpetrators, and locations. J Epidemiol Community Health. 2016. https://doi.org/10.1136/jech-2015-205860.

47. Branson N, Hofmeyr C, Lam D. Progress through school and the determinants of school dropout in South Africa. Dev South Afr. 2014;31:106-26. https://doi.org/10.1080/0376835X.2013.85361 0 .

48. Hosmer DW, Jovanovic B, Lemeshow S. Best subsets logistic regression. Biometrics. 1989;45:1265-70.

49. Colvin CJ. Strategies for engaging men in HIV services. Lancet HIV. 2019;6(3):e141-204.

50. Birdthistle I, Schaffnit SB, Kwaro D, Shahmanesh M, Ziraba A, Kabiru CW, et al. Evaluating the impact of the DREAMS partnership to reduce HIV incidence among adolescent girls and young women in four settings: a study protocol. BMC Public Health. 2018;18:1-15. https://doi.org/10.1186/s12889-018-5789-7.

51. Sa S, Aa M, Saul J, Motsa-Nzuza N, Kwesigabo G, Buluma R, et al. Prevalence of sexual violence against children and use of social services - seven countries, 2007-2013. MMWR Morb Mortal Wkly Rep. 2015. https://doi.org/10.1145/2660267.2660325.

52. Lowenthal ED, Bakeera-Kitaka S, Marukutira T, Chapman J, Goldrath K, Ferrand RA. Perinatally acquired HIV infection in adolescents from sub-Saharan Africa: a review of emerging challenges. Lancet Infect Dis. 2014;14:627-39.

53. Doyle AM, Mavedzenge SN, Plummer ML, Ross DA. The sexual behaviour of adolescents in sub-Saharan Africa: patterns and trends from national surveys. Trop Med Int Health. 2012. https:// doi.org/10.1111/j.1365-3156.2012.03005.x.

Publisher's Note Springer Nature remains neutral with regard to jurisdictional claims in published maps and institutional affiliations. 